\title{
Diagnosing Dry Eyes in Post-Menopausal Women using Schirmer's Test in Open and Closed Eyes without Anesthesia
}

\author{
Article by JayaRajini Vasanth ${ }^{1}$, Divyalakshmi ${ }^{2}$ \\ 1,2 Sri Ramachandra Medical College \& Research Institute, Chennai \\ E-mail:1'harshrajvas@yahoo.com
}

\begin{abstract}
Objectives: To compare the wettability and wetting time between open and closed eyes of post menopausal women using Schirmer's test without anaesthesia (ST) and to assess the number of dry eyes in open (STO) and closed (STC) schirmer test.

Methods: One-Hundred and Twenty eyes of 60 normal Post-Menopausal women were recruited from Sri Ramachandra University. Schirmer test (ST) was performed in a closed environment with the absence of air flow. This procedure was performed with the subjects both eyes open and closed with an interval of 1 hour and were conducted in 5 minutes. If wetting values are $35 \mathrm{~mm}$ before 5 minutes, wetting time should be recorded.

Results: In this study 120 eyes of 60 Post-menopausal women were included. Measurements of $S T_{I}$ performed with open eyes $(27.0 \pm 9.5)$ were higher statistical different from those performed with closed eyes $(17.5 \pm 11.0)$ in right eye of the patients. Measurements of $S T_{I}$ performed with open eyes $(27.5 \pm 9.9)$ were higher statistical different from those performed with closed eyes $(19.0 \pm 11.4)$ in left eye of the patients. Wetting time of $S T_{I}$ performed with open eyes $(4.1 \pm 1.2)$ were lower statistical different from those performed with closed eyes $(4.7 \pm 0.8)$ in right eye of the patients. Wetting time of $S T_{I}$ performed with open eyes $(4.1 \pm 1.2)$ were lower statistical different from those performed with closed eyes (4.6 \pm 0.8$)$ in left eye of the patients. The $p$ value from measurements of $S T_{I}$ for right and left eye was 0.0005 and the $p$ value from wetting time for right and left eye was 0.0005, so, there was a significant change between open and closed eyes.

Conclusion: ST performed with open and closed eyes can have an important influence in the diagnosis of dry eyes in post-menopausal women.
\end{abstract}

Keywords: Dry eyes, Post-menopausal women, Opened schirmer's test, closed schirmer's test.

\section{Introduction}

The International Dry Eye Workshop ${ }^{(1-2)}$, states that dry eye is a multifactorial disease of the tears and ocular surface that results in symptoms of discomfort, visual disturbance, and tear film instability with potential damage to the ocular surface. Dry eye often provokes variable symptoms; from light ocular discomfort to incapacity in keeping the eyes open ${ }^{(3-4)}$.

Tears are fluid secreted by the lacrimal glands of the eye which helps to moisten the eyes. Tears contain a wide variety of biologically active substances like mucin, electrolytes and other substances. Tears contain proteins including lysozyme, serum albumin etc. which have important functions.

Documented risk factors of dry eye are age, post-menopausal women, arthritis, caffeine use, thyroid disease, gout, total to high density lipoprotein cholesterol ratio, diabetes, multivitamin use and such occupational factors. Menopause is a remarkable event in the reproductive life of a woman. The dramatic fall in circulating estradiol levels at menopause impacts many tissues, the eye being one of the target organs. Dry eye complaint is commonly seen in postmenopausal women than men of the same age group, which may be attributed to androgen deficiency or just an imbalance between the two hormones ${ }^{(5)}$.

Dry eye diagnosis is based on the clinical features and some diagnostic tests. Schirmer test (ST) is one of the most used diagnostic tools in evaluating ocular surface status. Other tests like red phenol thread, break-up-time, rose bengal, fluorescein, lissamine green, impression 
cytology, biochemist analysis of the tear, interferometry, meniscometry and osmolarity measurement are also used ${ }^{(6-10)}$.

ST was first described by Otto Schirmer in 1903 and consists of the use of what man number 41 special strip, with $5 \mathrm{~mm}$ width and $35 \mathrm{~mm}$ length placed in lower eyelid. Schirmer test was divided into Schirmer I test (without anaesthesia) and Schirmer test II (with topical anaesthesia). When performed without anaesthesia, the $\mathrm{ST}_{\mathrm{I}}$ measures the basal tear secretion with the conjunctival-lacrimal trigeminal reflex and the function of the main lacrimal gland whose secretory activity is stimulated by the irritating nature of the filter paper. $\mathrm{ST}_{\text {II }}$ performed after topical anaesthesia measures the function of the basal lacrimal secretion $(6,7,10,11)$.

Schirmer originally described the test to be conducted with the patient seated, with open eyes, blinking freely. Various authors have published articles using the test with the patients remaining with closed eyes ${ }^{(12-15)}$, however, no study found evidence that such results are equivalents to the originally described tests by Schirmer. Recently, according to the 2007 Report of the International Dry Eye Workshop (DEWS), suggested to perform the Schirmer test with the patient's eyes closed ${ }^{(1)}$.

The purpose of this study is to compare the wettability and wetting time between open and closed eyes using Schirmers test (ST) and also to assess the number of dry eyes in post menopausal women using open (STO) and closed (STC) schirmer test.

\section{Methods and materials}

One-Twenty eyes of 60 normal Post-Menopausal volunteers attending the ophthalmology clinic, Sri Ramachandra University and research institute in porur were recruited into the study. Informed consent had obtained from all subjects. All participants underwent a routine ocular evaluation. Patients with lid disorders, any other ocular surface disorder, any eye surgery, diabetes, rheumatoid arthritis, thyroid disease, gout and any gynaecology disease were excluded. Contact lens wearers and patients with any kind of ocular and systemic medications were also excluded.

ST was performed in a closed environment with the absence of airflow. This procedure was performed with the subjects' both eyes open and closed with an interval of 1 hour. The schirmer strips were placed under the lower eyelid at the lateral side of the cornea, avoid touching the cornea. The length of the wetting strips were recorded after 5 minutes with the both eyes open. The patient was asked to blink freely. After one hour, schirmer strips were placed upon the same point in the same person again for 5 minutes, with the both eyes closed. If wetting values are $35 \mathrm{~mm}$ before 5 minutes, wetting time should be recorded.

\section{Literature review}

The study was done by Leão Gabbay Serruya, Daniel Cruz Nogueira, Richard Yudi Hida concluded that wetting values with open eyes showed significantly higher values when compared to closed eyes in normal individuals. This could probably be explained by the influence of the strip on reflex tearing during blinking. So ST performed with closed eye could diminish variations of humidity, evaporation and specially reflex tearing. The authors believe that the Schirmer test performed with closed eyes could eliminate environmental factors like evaporation and humidity.

Mohsen Bahmani-Kashkouli, Gholam-Hossein Aghai, Khalil Ghasemi-Falavarjani, Arezoo Astaraki, Hoora Mirzajani, Farzaneh Agha Mohammadi said that One-minute ST in both open and closed eyes is valuable alternative to conventional 5-minute ST. It provides faster and more comfortable measurements in normal subjects; however, its effect on dry eye patients requires complementary studies.

Serin D, Karsloğlu S, Kyan A, Alagöz G study concluded that ST with the patient's eyes closed produces less variable results and more repeatability than STO in normal subjects. Although their results may not extend to dry eye patient populations, they propose that STC 
without anaesthesia can be considered by those ophthalmologists who frequently use the ST as an adjunct to the differential diagnosis of dry eye.

$\mathrm{Na} \mathrm{Li}$, Xin-Guo Deng, and Mei-Feng He found a study that our study showed that ST I after topical anaesthesia with $0.5 \%$ proparacaine hydrochloride eye drops was more objective and reliable than that without anaesthesia in reflecting the status of $\mathrm{DE}$, and its diagnostic value in patients with ADDE was even higher.

Mohana Majumdar, Rekha Khandelwal, Tanya Gangwani concluded that Dry eye prevalence has significant association with elderly women with symptoms of dry eye. Hence, examination for dry eye should be an integral part of the assessment of post-menopausal women, especially those who are symptomatic.

\section{Statistical analysis}

The collected data were analysed with IBM.SPSS statistics software 23.0 Version. To describe about the data descriptive statistics frequency analysis, percentage analysis were used for categorical variables and the mean \& S.D were used for continuous variables. The Shapiro Wilk's test for Normality showed the data was skewed data; hence to find the significant difference between the bivariate samples in Paired groups (Open \& Closed) the Wilcoxon signed rank test was used. In the above statistical tools the probability value .05 is considered as significant level.

\section{Results}

One Hundred and Twenty eyes of 60 patients of Post-menopausal women were included in this study.

Table 1. Shows the mean and standard deviation of wetting values $(\mathrm{mm})$ of ST with open and closed eyes.

\begin{tabular}{|l|l|l|l|l|l|}
\hline \multicolumn{6}{|c|}{ Paired comparison by Wilcoxon signed rank test } \\
\hline \multicolumn{2}{|c|}{} & Mean & S.D & $\begin{array}{l}\text { Z- } \\
\text { Value }\end{array}$ & P-Value \\
\hline \multirow{2}{*}{ Pair 1 } & ROS & 27.0 & 9.5 & \multirow{2}{*}{6.096} & $0.0005 * *$ \\
\cline { 2 - 6 } & RCS & 17.5 & 11.0 & & \\
\hline \multirow{2}{*}{ Pair 2 } & LOS & 27.5 & 9.9 & \multirow{2}{*}{5.715} & $0.0005 * *$ \\
\cline { 2 - 5 } & LCS & 19.0 & 11.4 & & \\
\hline$* *$ Highly Significant at $\mathrm{P}<0.01$ level \\
\hline
\end{tabular}

ROS $=$ Right opened schirmer; RCS $=$ Right closed schirmer;

LOS $=$ Left opened schirmer; LCS $=$ Left closed schirmer; $\mathrm{ST}_{\mathrm{I}}$ in $\mathrm{mm}$.

Table 2. The mean value of measurements $(\mathrm{mm})$ of open $\mathrm{ST}_{\mathrm{I}}$ in right eye of the patients obtained was 27.0. The mean value of measurements of closed $\mathrm{ST}_{\mathrm{I}}$ in right eye of the patients obtained was 17.5. The mean value of measurements of open $\mathrm{ST}_{\mathrm{I}}$ in left eye of the patients obtained was 27.5. The mean value of measurements of closed $\mathrm{ST}_{\mathrm{I}}$ in left eye of the patients obtained was 19.0. In this study $\mathrm{p}<0.01$ value for open and closed eye $\mathrm{ST}_{\mathrm{I}}$ and there is a significant changes between open and closed eye.

\begin{tabular}{|l|l|l|}
\hline & Right eye & Left eye \\
\hline Open & 27.0 & 27.5 \\
\hline Closed & 17.5 & 19.0 \\
\hline
\end{tabular}


Texila International Journal of Academic Research

Volume 4, Issue 1, Jun 2017

Graph 1 shows that the wetting values $(\mathrm{mm})$ of $\mathrm{ST}_{\text {I }}$ performed with open eye showed higher statistical different than those performed with closed eye $(\mathrm{p}<0.01)$.

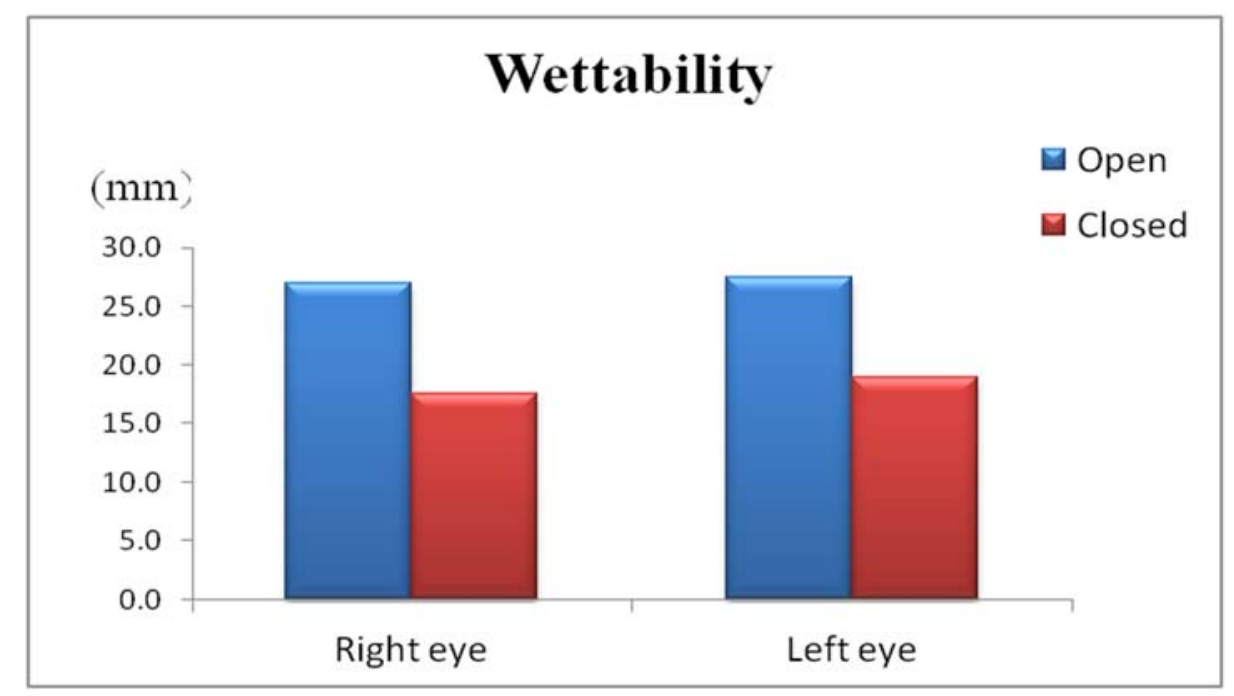

Graph 1: Wetting values of open and closed eyes

Table 3. Shows the mean and standard deviation of wetting time ( $\mathrm{min}$ ) of ST with open and closed eyes.

\begin{tabular}{|l|l|l|l|l|l|}
\hline \multicolumn{6}{|c|}{ Paired comparison by Wilcoxon signed rank test } \\
\hline \multirow{2}{*}{} & Mean & S.D & Z-Value & P-Value \\
\hline \multirow{3}{*}{ Pair 1 } & ROT & 4.1 & 1.2 & \multirow{2}{*}{4.326} & \multirow{2}{*}{$0.0005 * *$} \\
\cline { 2 - 6 } & RCT & 4.7 & 0.8 & & \\
\hline \multirow{3}{*}{ Pair 2 } & LOT & 4.1 & 1.2 & \multirow{3}{*}{4.45} & \multirow{2}{*}{$0.0005 * *$} \\
\cline { 2 - 5 } & LCT & 4.6 & 0.8 & & \\
\hline \multirow{2}{*}{$* *$ Highly Significant at P $<0.01$ level } \\
\hline
\end{tabular}

ROT $=$ Right open time; RCT $=$ Right closed time;

LOT $=$ Left open time; LCT $=$ Left closed time; Time in min

Table 4. The mean value of wetting time ( $\mathrm{min}$ ) in open $\mathrm{ST}_{\mathrm{I}}$ in right eye of the patients obtained was 4.1. The mean value of wetting time in closed $\mathrm{ST}_{\mathrm{I}}$ in right eye of the patients obtained was 4.7 . The mean value of wetting time in open $\mathrm{ST}_{\mathrm{I}}$ in left eye of the patients obtained was 4.1. The mean value of wetting time in closed $\mathrm{ST}_{\mathrm{I}}$ in left eye of the patients obtained was 4.6 . In this study $\mathrm{p}<0.01$ value for open and closed eye $\mathrm{ST}_{\mathrm{I}}$ and there is a significant changes between open and closed eye.

\begin{tabular}{|l|l|l|}
\hline & Right eye & Left eye \\
\hline Open & 4.1 & 4.1 \\
\hline Closed & 4.7 & 4.6 \\
\hline
\end{tabular}

Graph 2 shows that the wetting time (min) of $\mathrm{ST}_{\mathrm{I}}$ performed with open eye showed lower statistical different than those performed with closed eye $(\mathrm{p}<0.01) . \mathrm{ST}_{\mathrm{I}}$ performed with closed eyes had taken more time to wet than performed with open eyes. 


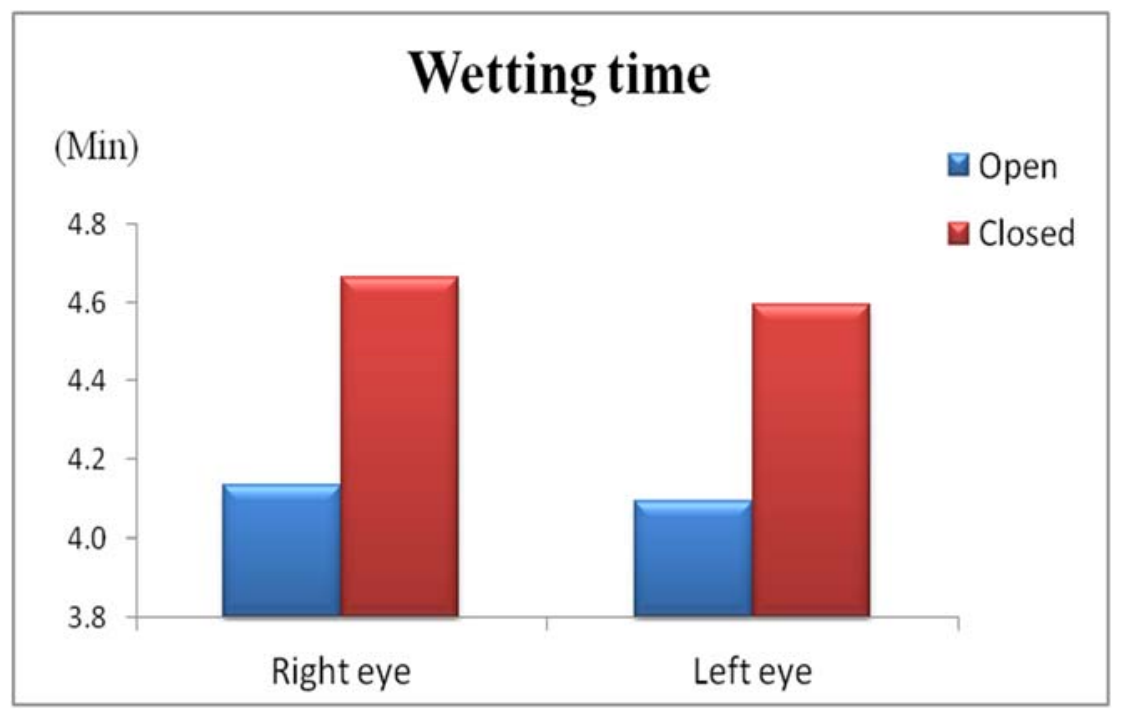

Graph 2. Wetting time of open and closed eyes

This study included 120 eyes of 60 post-menopausal women out of which $45 \%$ ( 54 eyes) were dry eyes in closed, $16.6 \%$ (20 eyes) were dry eyes in open and $16.6 \%$ (20 eyes) were dry eyes in both open and closed $\mathrm{ST}_{\mathrm{I}}$. This is showed in table 5

Table 5

\begin{tabular}{|l|l|l|l|}
\hline $\begin{array}{l}\text { Total no of } \\
\text { eyes }\end{array}$ & $\begin{array}{l}\text { No of } \\
\text { dry eyes } \\
\text { in closed }\end{array}$ & $\begin{array}{l}\text { No of dry } \\
\text { eyes in } \\
\text { Open }\end{array}$ & $\begin{array}{l}\text { No of dry eyes } \\
\text { in both Open } \\
\text { \& Closed }\end{array}$ \\
\hline 120 & $54(45 \%)$ & $20(16.6 \%)$ & $20(16.6 \%)$ \\
\hline
\end{tabular}

Table 6. Shows that number of dry eyes in open and closed based on their severity in post-menopausal women.

\begin{tabular}{|l|l|l|l|l|}
\hline Classification & $\begin{array}{l}\text { No of dry } \\
\text { eyes in } \\
\text { closed }\end{array}$ & $\%$ & $\begin{array}{l}\text { No of dry } \\
\text { eyes in } \\
\text { Open }\end{array}$ & $\%$ \\
\hline Mild & 14 & 11.6 & 10 & 8.33 \\
\hline Moderate & 25 & 20.9 & 9 & 7.5 \\
\hline Severe & 15 & 12.5 & 1 & 0.83 \\
\hline Normal & 66 & 55 & 100 & 83.34 \\
\hline Total & 120 & 100 & 120 & 100 \\
\hline
\end{tabular}

\section{Discussion}

According to DEWS definition and classification workshop ${ }^{(1)}$ explained the classification of dry eye based on their severity. They classified as Mild (range: $11 \mathrm{~mm}-14 \mathrm{~mm}$ ), Moderate (range: $6 \mathrm{~mm}-10 \mathrm{~mm})$, Severe $(0 \mathrm{~mm}-5 \mathrm{~mm})$ and it is normal if it is $\geq 15 \mathrm{~mm}$.

However, it is not mentioned if test is performed with open or closed eyes ${ }^{(3,6,11)}$. It was originally described with open eyes, allowing the patient to blink freely ${ }^{(3,6-7,11)}$. Some authors affirm that the results of the test do not differ when carried out with open or closed eyes ${ }^{(7-8)}$. 
Texila International Journal of Academic Research

Volume 4, Issue 1, Jun 2017

However, most studies do not mention which method was used in the tests (open or closed eyes) ${ }^{(16-21)}$. Many authors have published their results using the test with closed eyes ${ }^{(3,13-15)}$.

In this study, we noted that ST values for Post-Menopausal women shows about $45 \%$ of dry eyes in closed and about $16.6 \%$ of dry eyes in open. Therefore, it is necessary to accomplish other comparative studies in patients with dry eye, to determine values without the influence of open or closed eyes. Here there is a possibility of increasing false-positive rates of dry eye syndrome in closed eyes than in open eyes.

The factors promoting Dry Eye Syndrome (DES) include systemic autoimmune disease, hormonal changes, neurologic lesions, age-related changes, and iatrogenic and workplacerelated causes such as LASIK surgery and video display terminal use ${ }^{(22-23) .}$ The lacrimal gland also appears to undergo a number of age-related changes ${ }^{(24)}$ Several data in literature suggest a major influence of gender and sex hormones on the physiology of the lacrimal gland and that they are involved in the pathogenesis of DES.

It also occurs mainly in women and its appearance is frequently related to marked variations in serum sex hormone levels during menopause ${ }^{(25)}$. The data from a study done by Caterina Gagliano, et al suggest that low levels of androgen and high estrogen levels may cause not only a reduction in tear production leading to aqueous-deficient dry eye, but also a dysfunction in meibomian gland function determining an evaporative dry eye $\mathrm{e}^{(26)}$.

Thus, as in Beaver Dam Offspring Study prevalence of dry eye symptoms increased with age in women ${ }^{(27)}$.

ST has been found to give poor reproducibility for detecting aqueous tear deficiency because it is directly influenced by temperature, humidity, evaporation, reflex tearing. However, it is one of the most common diagnostic tests used worldwide to diagnose aqueous deficiency because it is easy to perform ${ }^{(6-7,11,21,28-29)}$. The low cost and simplicity of Schirmer test makes itself the most commonly used screening test for assessment of tear production.

\section{Conclusion}

Schirmer wetting values in open eyes shows higher significant values when compared to closed eyes in post-menopausal women. This in turn results in number of dry eyes in closed is more than in open eyes. This could because of androgen deficiency, a critical etiologic factor in the pathogenesis of aqueous-deficient dry eye syndrome during menopause. Then it also shows that the wetting time taken for open eyes is lesser duration than for closed eyes. This could probably be explained by the influence of the strip on reflex tearing during blinking. When the eyes are closed, the role of the lid margins and eyelashes in stimulating tear secretion and the influence of external factors such as temperature, evaporation, and humidity are reduced.

As a routine, Schirmers test in both open and closed eyes to be included in the existing protocol of comprehensive eye examination to rule out dry eyes.

\section{References}

[1]. Adam J, Paulsen J Cruickshanks, Mary E Fischer, Guan-Hua Huang, Barbara EK, Klein Ronald, Klein Dayna, S Dalton. Dry Eye in the Beaver Dam Offspring Study: Prevalence, Risk Factors, and Health-Related Quality of Life. Am J Ophthalmol. Volume 157, Issue 4, Pages 799-806, April 2014.

[2]. Bawazeer AM, Hodge WG. One-minute Schirmer test with anesthesia. Cornea. 2003; 22 (4):285-7. Comment in: Cornea. 2004;23(3):318-9; author reply 319.

[3]. Clinch TE, Benedetto DA, Felberg NT, Laibson PR. Schirmer's test. A closer look. Arch Ophthalmol. 1983; 101(9):1383-6.

[4]. Caterina Gagliano, Salvatore Caruso, Giuseppe Napolitano, Giulia Malaguarnera. Low levels of $17-\beta$-oestradiol, oestrone and testosterone correlate with severe evaporative dysfunctional tear syndrome in postmenopausal women: a case-control study. Br J Ophthalmol 2014; 98: 371-376 doi: 10.1136/bjophthalmol-2012-302705.

[5]. Cho P, Yap M. Schirmer test II. A clinical study of its repeatability. Optom Vis Sci. 1993; 70(2):157-9. 
[6]. Cho P, Yap M. Schirmer test I. A review. Optom Vis Sci. 1993; 70(2):152-6.

[7]. Design and conduct of clinical trials: Report of the Clinical Trials Subcommittee of the International Dry Eye Work Shop (2007). Ocul Surf. 2007; 5(2):153-62.

[8]. Debra A Schaumberg, David A Sullivan, Julie E Buring et al. Prevalence of dry eye syndrome among US women. Am J Ophthalmol. Volume 136, Issue 2, Pages 318-326, August 2003.

[9]. Gilbard JP, Rossi SR, Azar DT, Heyda KG. Effect of punctal occlusion by Freeman silicone plug insertion on tear osmolarity in dry eye disorders. ClaoJ. 1989; 15(3):216-8.

[10]. Hida RY, Mascaro VL, Hofling-Lima AL, Goto E, Tsubota K, Gomes JA. Métodos Diagnósticos. In: Gomes JA, Alves MR, editores. Superfície ocular. Rio de Janeiro: Cultura Médica; 2006.

[11]. Hida RY, Nishiwaki-Dantas MC, Hida MM, Tsubota K. [Quantitative tear study using the red phenol test in the Brazilian population]. Arq Bras Oftalmol. 2005; 68(4):433-7. Portuguese.

[12]. Korb DR. Survey of preferred tests for diagnosis of the tear film and dry eye. Cornea. 2000; 19(4):483-6.

[13]. Lemp MA. Recent developments in dry eye management. Ophthalmology. 1987; 94(10):1299304.

[14]. Lemp MA. Report of the National Eye Institute/Industry workshop on Clinical Trials in Dry Eyes. CLAO J. 1995; 21(4):221-32.

[15]. Lemp MA. Keratoconjunctivitis sicca (introduction in the cornea). In: C.S. Foster, D.T. Azar, C.H. Dohlman (Eds.) Scientific foundations and clinical practice. Lippincott Williams and Wilkins, Philadelphia; 2005: 573-576.

[16]. Lima CG, Siqueira GB, Cardoso IH, Sant'Anna AE, Osaki MH. [Evaluation of dry eye in the preoperative and postoperative period of blepharoplasty]. Arq Bras Oftalmol. 2006; 69(3):327-82. Portuguese.

[17]. Michael A. Lemp. Dry Eye (Keratoconjunctivitis Sicca), Rheumatoid Arthritis, and Sjögren's Syndrome. Am J Ophthalmol. Volume 140, Issue 5, Pages 898-899, November 2005.

[18]. Nishiwaki-Dantas MC. Olho seco. Arq Bras Oftalmol. 19990; 62(1):101-5.

[19]. Nichols KK, Mitchell GL, Zadnik K. The repeatability of clinical measurements of dry eye. Cornea. 2004; 23(3):272-85.

[20]. Nichols KK, Nichols JJ, Mitchell GL. The lack of association between signs and symptoms in patients with dry eye disease. Cornea. 2004; 23(8):762-70.

[21]. Nichols KK, Nichols JJ, Lynn Mitchell G. The relation between tear film tests in patients with dry eye disease. Ophthalmic Physiol Opt. 2003; 23(6):553-60.

[22]. Ogawa Y, Okamoto S, Wakui M, Watanabe R, Yamada M, Yoshino M, et al. Dry eye after haematopoietic stem cell transplantation. Br J Ophthalmol. 1999; 83(10):1125-30.

[23]. Research in dry eye: Report of the Research Subcommittee of the International Dry Eye Work Shop (2007). Ocul Surf. 2007; 5(2):179-93.

[24]. Versura P, Campos EC. Menopause and dry eye. A possible relationship. Gynecol Endocrinol 2005; 20(5):289-98.

[25]. Shimazaki J, Shimmura S, Fujishima H, Tsubota K. Association of preoperative tear function with surgical outcome in severe Stevens-Johnson syndrome. Ophthalmology. 2000; 107(8):1518-23.

[26]. Shimazaki J, Sakata M, Tsubota K. Ocular surface changes and discomfort in patients with meibomian gland dysfunction. Arch Ophthalmol 1995; 113: 1266-70.

[27]. Toda I, Asano-Kato N, Komai-Hori Y, Tsubota K. Dry eye after laser in situ keratomileusis. Am J Ophthalmol. 2001; 132(1):1-7.

[28]. Tsubota K. Tear dynamics and dry eye. Prog Retin Eye Res. 1998;17(4):565-96.

[29]. Tsubota K. The importance of the Schirmer test with nasal stimulation. Am J Ophthalmol. 1991; 111(1):106-8. 